Open Access

\title{
The NULevel trial of a scalable, technology- assisted weight loss maintenance intervention for obese adults after clinically significant weight loss: study protocol for a randomised controlled trial
}

Elizabeth H. Evans', Vera Araújo-Soares', Ashley Adamson 1,2,3, Alan M. Batterham4, Heather Brown', Miglena Campbell', Stephan U. Dombrowski ${ }^{5}$, Alison Guest ${ }^{1}$, Daniel Jackson ${ }^{6}$, Dominika Kwasnicka ${ }^{1,2}$, Karim Ladha ${ }^{6}$, Elaine McColl ${ }^{1,9}$, Patrick Olivier ${ }^{6}$, Alexander J. Rothman ${ }^{7}$, Kirby Sainsbury ${ }^{1}$, Alison J. Steel ${ }^{9}$, Ian Nicholas Steen ${ }^{1}$, Luke Vale ${ }^{1}$, Martin White ${ }^{8}$, Peter Wright ${ }^{6}$ and Falko F. Sniehotta ${ }^{1,2^{*}}$

\begin{abstract}
Background: Effective weight loss interventions are widely available but, after weight loss, most individuals regain weight. This article describes the protocol for the NULevel trial evaluating the effectiveness and cost-effectiveness of a systematically developed, inexpensive, scalable, technology-assisted, behavioural intervention for weight loss maintenance (WLM) in obese adults after initial weight loss.

Methods/Design: A 12-month single-centre, two-armed parallel group, participant randomised controlled superiority trial is underway, recruiting a total of 288 previously obese adults after weight loss of $\geq 5 \%$ within the previous 12 months. Participants are randomly assigned to intervention or control arms, with a 1:1 allocation, stratified by sex and percentage of body weight lost ( $<10 \%$ vs $\geq 10 \%)$. Change in weight (kg) from baseline to 12 months is the primary outcome. Weight, other anthropometric variables and 7-day physical activity (assessed via accelerometer) measures are taken at 0 and 12 months. Questionnaires at 0,6 and 12 months assess psychological process variables, health service use and participant costs. Participants in the intervention arm initially attend an individual face-to-face WLM consultation with an intervention facilitator and then use a mobile internet platform to self-monitor and report their diet, daily activity (via pedometer) and weight through daily weighing on wirelessly connected scales. Automated feedback via mobile phone, tailored to participants' weight regain and goal progress is provided. Participants in the control arm receive quarterly newsletters (via links embedded in text messages) and wirelessly connected scales. Qualitative process evaluation interviews are conducted with a subsample of up to 40 randomly chosen participants. Acceptability and feasibility of procedures, cost-effectiveness, and relationships among socioeconomic variables and WLM will also be assessed.

(Continued on next page)
\end{abstract}

\footnotetext{
* Correspondence: falko.sniehotta@ncl.ac.uk

${ }^{1}$ Institute of Health \& Society, Newcastle University, Baddiley-Clark Building, Richardson Road, Newcastle upon Tyne NE2 4AX, UK

${ }^{2}$ Fuse, the UK CRC Centre for Translational Research in Public Health, Institute of Health \& Society, Newcastle University, Baddiley-Clark Building, Richardson Road, Newcastle upon Tyne NE2 4AX, UK

Full list of author information is available at the end of the article
}

C Biomed Central

(c) 2015 Evans et al. Open Access This article is distributed under the terms of the Creative Commons Attribution 4.0 International License (http://creativecommons.org/licenses/by/4.0/), which permits unrestricted use, distribution, and reproduction in any medium, provided you give appropriate credit to the original author(s) and the source, provide a link to the Creative Commons license, and indicate if changes were made. The Creative Commons Public Domain Dedication waiver (http://creativecommons.org/publicdomain/zero/1.0/) applies to the data made available in this article, unless otherwise stated. 
(Continued from previous page)

Discussion: It is hypothesised that participants allocated to the intervention arm will show significantly lower levels of weight regain from baseline than those in the control arm. To date, this is the first WLM trial using remote realtime weight monitoring and mobile internet platforms to deliver a flexible, efficient and scalable intervention, tailored to the individual. This trial addresses a key research need and has the potential to make a vital contribution to the evidence base to inform future WLM policy and provision.

Trial registration: http://www.isrctn.com/ISRCTN14657176 (registration date 20 March 2014).

Keywords: Behaviour, Randomised controlled trial, Clinical protocol, Obesity, Overweight, Weight loss, Weight loss maintenance

\section{Background}

Obesity remains a major public health concern worldwide [1]. It is strongly associated with chronic illness, sickness, absence from work, reduced life expectancy and costs the UK economy $£ 16$ billion per year [2]. The prevalence of obesity and consequent ill health are more marked amongst the most socioeconomically deprived, contributing to health inequalities [1]. It is commonly recommended that obese adults aim for a clinically significant weight loss of at least 5-10 \% body weight [3].

Behavioural weight loss interventions typically produce initial, clinically significant weight loss $[4,5]$ and such evidence-based interventions are now widely available [6]. However, most people regain a third of the lost weight within a year and the rest within 3-5 years [4]. The health benefits of weight loss can only be achieved if it is maintained over the longer term [7]. Helping people to avoid weight regain after successful weight loss is therefore vital to tackle obesity and its consequences. Although evidence suggests that extended care interventions can slow down weight regain, there is to date a lack of scalable evidence-based interventions to support people after successful weight loss [8, 9]. It is currently not known how best to support individuals who have lost weight to prevent or slow down weight regain [10]. This gap in the evidence limits the impact of services that elicit the initial weight loss.

\section{Rationale and development of the NULevel intervention}

The NULevel intervention was developed, following Medical Research Council (MRC) guidance for the development of complex interventions [11], to provide scalable weight loss maintenance (WLM) support (i.e. an intervention that is inexpensive, independent of location and specific resources, flexible and tailored to individual support needs). To achieve this aim, NULevel utilises an automated remote weight-monitoring and feedback system using participants' mobile phones as the main mode of delivery. Standard digital body weight scales have been modified to transmit body weight data to a central server through the mobile phone network in real time. The bespoke NULevel interface stores and processes incoming information to provide both automated feedback for the participant and a data hub for the intervention team. The use of personal weighing scales is central to NULevel. Frequent self-weighing is associated with better WLM [12-14]. In NULevel, regular self-weighing enables personal tailoring of intervention content based on an underlying 'traffic light' system, allowing the intervention to be less intensive when the participant's body weight is stable and more intensive at times when body weight is increasing [15]. Mobile phones were chosen as a flexible and ubiquitous digital communication platform (e.g. $93 \%$ of adults in the UK personally own/use a mobile phone [16]), which allow access to text messages and mobile internet content, as well as enabling communication with the intervention delivery team. In NULevel, mobile phones are also used to tailor the content and intensity of the intervention in response to participantprovided information. Participants are prompted once a week to report their step counts, progress on personalized eating goals, mood, goal priority, satisfaction with and confidence for weight loss maintenance. They can also request further contact with the intervention team.

NULevel was developed based on a recent systematic review of randomised controlled trials (RCTs) of WLM interventions for obese adults after clinically significant weight loss [9]. The review found that complex interventions, targeting both dietary and physical activity behaviours, significantly reduced weight regain. There was no evidence for a dose-response relationship. Moreover, no evidence for the effectiveness of exclusively internetdelivered interventions was found [9]. Formative qualitative research for this project suggested that an initial face-to-face contact with the intervention provider may increase participants' motivation to engage with internet-delivered elements of a complex intervention [17]. NULevel starts, therefore, with an individual face-to-face WLM consultation to facilitate the transition from weight loss to WLM.

The NULevel content was informed by further analyses of the review data to identify theories, behaviour change techniques and intervention components associated with effective interventions [9], a systematic review 
of theories of behavioural maintenance [18], evidence from the US National Weight Control Registry [19], qualitative research $[17,20,21]$ and intensive user-centred design.

\section{Current trial}

The NULevel trial is the first RCT of a systematically developed WLM intervention utilising remote real-time weight monitoring and mobile internet platforms to deliver a scalable intervention, tailored to the individual. With a few exceptions (e.g. [15, 22, 23]), most previous WLM trials induced weight loss before randomisation. NULevel is recruiting initially obese individuals who have lost weight through a range of different strategies, including self-directed efforts and commercial weight loss programmes.

The primary aim of NULevel is to evaluate the effectiveness of an inexpensive, scalable, technology-assisted, behavioural intervention for reducing weight regain among obese adults after initial weight loss. Secondary objectives are: (1) to test the acceptability and feasibility of the trial procedures through an integrated internal pilot study involving the first 50 participants in the trial, (2) to estimate the effectiveness and cost-effectiveness of the behavioural intervention in maintaining weight loss, and (3) to elucidate any associations among socioeconomic variables and WLM.

\section{Methods/Design}

This is a single-centre, two-armed, parallel group, participant randomised controlled superiority trial designed to compare the effectiveness and cost-effectiveness of a newly developed WLM intervention against a minimal intensity control condition over 12 months. Participant flow through the study is illustrated in Fig. 1. Ethics approval was obtained 6 February 2014 from the East MidlandsDerby National Research Ethics Service (REC: 14/EM/ 0069). The trial has been registered on the ISRCTN registry (ISRCTN14657176: http://www.controlled-trials.com/ ISRCTN14657176).

\section{Participants and inclusion criteria}

The aim is to recruit 288 adults ( $\geq 18$ years). Individuals are eligible to participate if they meet the following eligibility criteria:

1. A body mass index (BMI) of $\geq 30 \mathrm{~kg} / \mathrm{m}^{2}$ any time in the 24 calendar months preceding trial entry (i.e. the date of consent); the BMI threshold is $\geq 28 \mathrm{~kg} / \mathrm{m}^{2}$ for individuals of South Asian descent [24];

2. A weight loss of $\geq 5 \%$ in the 12 calendar months preceding trial entry. Written verification of this weight loss should be provided by a physician, weight loss counsellor or friend; if no such evidence from a third party is available, participants may selfcertify their weight loss;
3. Ordinarily living or working in the North East of England;

4. Access to and willingness to use an internet-enabled mobile telephone in order to receive messages from the research team, containing embedded links to relevant online content;

5. Ability to use a standing scale for weight measurements.

Individuals are excluded from participation on the following grounds:

1. Participation in prior development studies of the intervention;

2. Weight loss due to illness or surgical procedures, including bariatric surgery;

3. Pregnancy or plans to become pregnant in the next year;

4. Breastfeeding an infant under 6 months of age;

5. Current involvement in other weight intervention research studies;

6. Inability to understand written material or telephone conversations in English;

7. A diagnosis of anorexia nervosa, bulimia nervosa or purging disorder, or of any condition which may preclude increasing mild to moderate physical activities such as walking;

8. Baseline weight of $>175 \mathrm{~kg}$ (due to the measurement range of the provided scales);

9. Plans to leave the area or to undertake long-term travel in the forthcoming 12 months.

\section{Participant identification and recruitment}

Participants are recruited via commercial weight loss providers (e.g. Slimming World and Lighter Life), local authority-commissioned adult weight management programmes, social media including Facebook and Twitter and other forms of community recruitment including web advertisements, and flyers and posters in local venues.

\section{Screening and consent}

Interested individuals are asked to complete an online enquiry form, providing data to enable an initial eligibility assessment to be made. A research team member evaluates the provided information against the inclusion and exclusion criteria and informs the interested individual of their eligibility status via email. Individuals who provisionally meet the inclusion criteria then receive, by email, the study information sheet and a letter of invitation to attend a baseline appointment with a research team member, optionally at a university venue or at the participant's home. At this appointment, their eligibility status is formally determined and they are offered the option of asking any questions about the study information sheet and/or their 


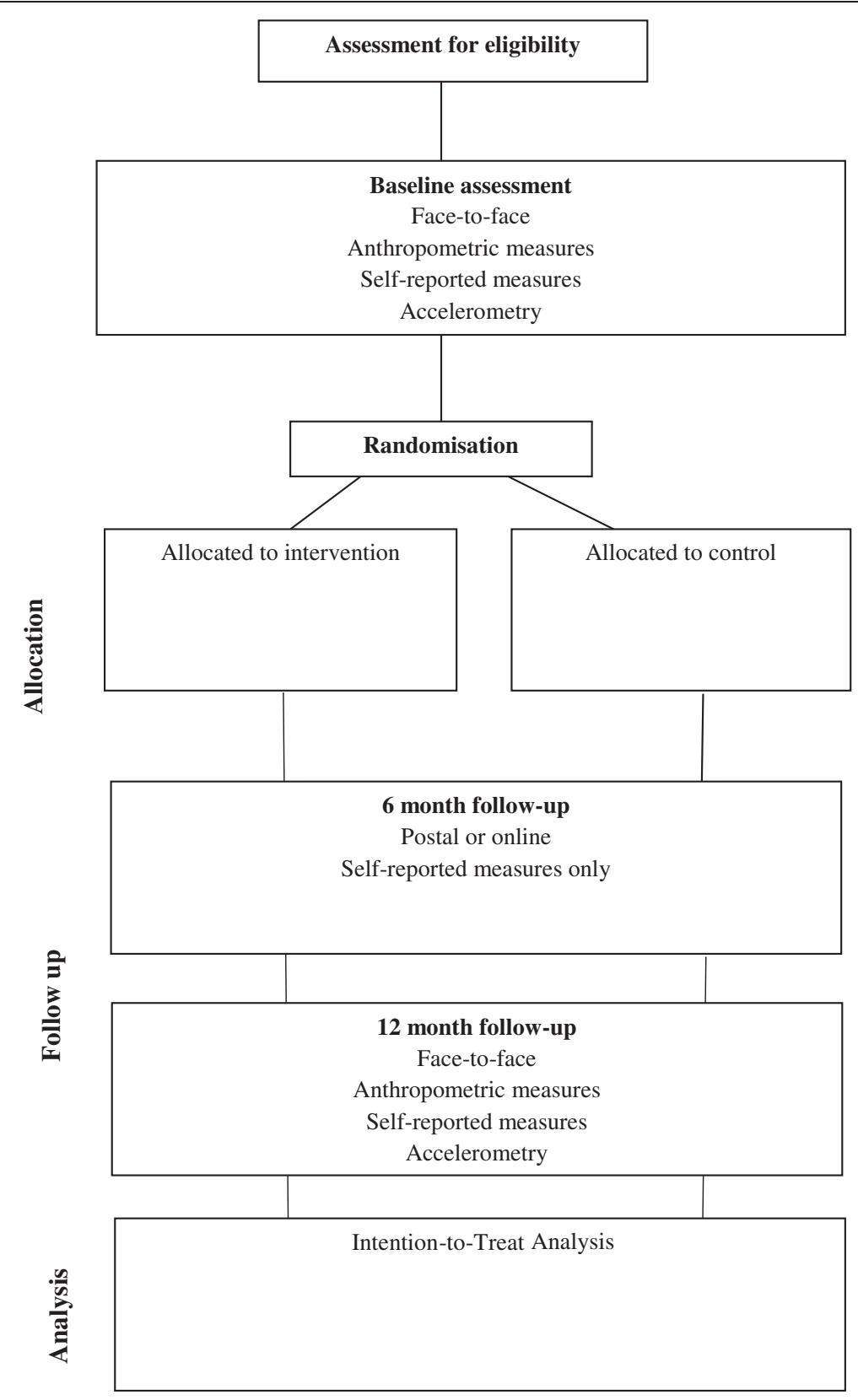

Fig. 1 Planned recruitment, allocation and follow-up for the NULevel trial

participation. Once any questions have been answered, the outcome assessor reiterates the conditions of consent, including that all data collected will remain confidential and they are free to withdraw at any time throughout the study. Participants then sign the consent form in the presence of the outcome assessor.

\section{Interventions}

\section{Allocation of wirelessly connected scales}

At the end of the baseline assessment, every participant (intervention and control arm) receives a wirelessly connected scale. The scales have a standard digital display showing the user their current weight in their choice of units. For data transmission, the scales use the mobile phone network to avoid the need for any infrastructure or connectivity requirements in participants' homes. To maximize coverage, a 'multi-network' SIM card allows the scales to select between multiple service providers based on the available signal. Even with multiple networks to choose from, mobile internet connectivity is not universal; instead, the basic GSM short message service (SMS) is used to transmit weights, which only requires that the 
scales can register with any network. Mobile phone technology requires significantly more power than standard scales, and battery-powered devices typically require regular recharging. The wirelessly connected scales were engineered to last for up to 12 months on a single set of batteries, and are therefore suitable for use. ${ }^{1}$

Every time participants weigh themselves, the recorded weight is transmitted over the mobile phone network to a central server and delivered into the software used to administer the digital elements of the intervention in real time. Weights are automatically recorded, dated and timestamped for each participant. Participants are informed that only those randomised to the intervention arm receive feedback on their weight progress.

\section{The NULevel intervention}

The intervention is delivered using a combination of a single face-to-face contact; automated messages in response to weighing data and weekly questionnaires delivered as mobile web content (text message with internet link) and text messages generated by the intervention team. On request of the participant, individual telephone calls with a member of the research team can be scheduled to discuss specific problems with WLM. NULevel is primarily based on self-regulation theory [25]. It uses technology to facilitate the monitoring of weight, behavioural goals and risk factors for lapses and it provides feedback and reinforcement. As such it is based on effective behavioural principles $[15,26]$. This approach also allows tailoring of intervention components to the participants' progress.

\section{Initial face-to-face WLM consultation}

Each participant allocated to the intervention arm of the trial is invited to attend an initial individual face-toface WLM consultation with a psychologist, trained to deliver the NULevel intervention (facilitator), either at the university site or another agreed venue. Prior to this session, each participant receives by post a weight management history questionnaire, an Omron III Walking Style pedometer (Omron UK Ltd, Milton Keynes, UK) and a food diary to record over 4 days (including at least one weekend day) what they eat and drink, and how many steps they take based on the pedometer readings. They bring the food diary, pedometer and completed questionnaire to their WLM consultation. The consultation takes between 60 and 90 minutes. The main aims of the session are to build rapport, to ensure that the participant has a clear, sustainable and healthy plan of how to keep the lost weight off, and to gather information from the participant to personalise subsequent intervention contacts. The detailed structure, objectives, and behaviour change techniques of the session are summarised in Table 1.

Participants discuss their weight history with the intervention facilitator. They are then supported to formulate and plan for specific weight, dietary and physical activity maintenance goals, and to undertake problem solving to identify likely barriers and possible solutions to achieving these maintenance goals. When setting weight goals, participants identify weight thresholds to define a personal 'traffic light' system to monitor their weight. The traffic light system helps to tailor the intervention to individual progress. They define a 'green zone', e.g. a desired weight corridor that indicates that their WLM is on target, a 'yellow zone' when weight is increasing and a 'red zone' when weight regain is substantial [15]. The thresholds for the yellow and red zone are usually set at $2.5 \%$ and $5 \%$ over the baseline weight respectively, but participants can personalise these thresholds in accordance to their body weight and previous weight loss. They can also readjust their traffic light system later if substantial weight changes occur. Participants learn that NULevel will offer more support to tackle regain and intervention contacts will become more frequent if their weight exceeds the yellow zone weight threshold for 4 consecutive days. Participants are encouraged to maintain existing healthy weight management practices if such practices are sustainable, and if the participant wishes. This may include the use of local authority or commercial weight loss services. When participants' weight exceeds the red zone weight threshold for 4 consecutive days, a member of the intervention team initiates a review of current WLM goals and behaviours and provides additional support (see Table 2).

\section{SMS short message service}

Participants are then introduced to the web-based intervention platform and shown how to enter information about their selected dietary behaviours and physical activity (step counts) against their goals in a weekly 'diary entry'. Feedback on the diary entry prompts participants to reflect on their progress towards the personal dietary and activity goals, identified during the face-to-face WLM consultation; they are also prompted to rate their motivation and confidence to maintain their weight in the coming week. Figure 2 provides an example screenshot from the NULevel mobile web interface.

Participants are provided with a paper-based guide to self-monitoring their weight, physical activity and dietary progress, shown an example of a completed diary entry, and informed of their user name and password. They learn how the tailored SMS feedback allows them to evaluate their progress towards their outcome goal (weight) and behavioural goals (dietary and physical activity) in response to the information they enter each 
Table 1 Summary of the NULevel face-to-face weight loss maintenance consultation

\begin{tabular}{ll}
\hline Section & Content/objectives \\
\hline Introduction (5 mins) & Welcome and consent; explain session structure \\
$\begin{array}{ll}\text { A: Weight history and goals } \\
\text { (10 mins) }\end{array}$ & Review weight history, overall trajectory and number of WL \\
& attempts \\
& Agree overall weight goal and regain thresholds for red and \\
& yellow zones \\
& Demonstrate and encourage weight self-monitoring using online \\
& study interface; explain weight-related SMS feedback system \\
& Review current weight management strategies and future \\
& preferences \\
B: Weight strategies and & Identify individual WL success factors: initial trigger(s); motivations; \\
success (10 mins) & duration; regain/setbacks; consequences \\
& $\begin{array}{l}\text { Review eating behaviours using 4-day food diary (habits,frequency; } \\
\text { nutritional adequacy; context; any uncontrolled eating; whether } \\
\text { participant desires any dietary changes) }\end{array}$ \\
C: Dietary review & Identify specific foods/drinks that participant overeats and finds \\
(10 mins) & hard to control/avoid (trigger foods); identify less problematic \\
& alternatives \\
& Identify and formulate $\geq 1$ SMART eating goals for WLM, specifying \\
how, where and when behaviour is performed, potential sources \\
of social support, barriers, and possible solutions \\
Agree plan against which participant monitors and evaluates own \\
performance
\end{tabular}

Discuss eating goal self-monitoring using online study interface Explain input of eating data to online 'diary', SMS feedback and goal review/resetting process

E: Coping plans for tempting Identify situations in which participant struggles to adhere to situations (5 mins) desired eating habits. Participant generates strategies to avoid this outcome

Behaviour change techniques

Prompting focus on past success

Goal setting (outcome)

Prompt self-monitoring of behavioural outcome

Selection of behavioural options

Prompt focus on past success

Provide feedback on performance

Goal setting (behaviour)

Barrier identification

Problem solving

Goal setting (behaviour)

Problem solving

Action planning

Coping planning

Plan social support/social change

Prompt self-monitoring of behaviour

Review of behavioural goals

Barrier identification

Problem solving

Coping planning

Optional: identify an alternative WLM plan, if participant desires, from three options: Mediterranean diet, calorie-controlled diet and Change4life

Provide instruction on how to perform the behaviour and information on where/when to perform the behaviour

Discuss how, where, when and with whom to put the plan into place, possible obstacles to implementing the plan, and possible solutions to apply

\section{Action planning}

Coping planning

Barrier identification

Problem solving

F: Physical activity review and goal setting (10 mins)

G: Relapse prevention (10 mins)
Review and discuss current physical activity

Highlight importance of physical activity to WLM and overall health, and discuss ways to become more active, if desired

Identify and formulate a SMART physical activity goal for WLM (e.g. daily step count), specifying how, where and when behaviour is performed, potential sources of social support, barriers, and possible solutions

Discuss activity goal self-monitoring using online study interface Explain input of step counts to online 'diary', SMS feedback and goal review/resetting process

Explain rationale for behavioural self-monitoring, lapse/relapse distinction and importance of problem solving

Explain weekly online diary contains questions on WLM confidence; health, wellbeing and priority placed on WLM in
Provide feedback on performance

Provide information on the consequences of behaviour to the individual

Goal setting (behaviour)

Action planning

Barrier identification

Coping planning

Plan social support/social change

Prompt self-monitoring of behaviour

Review of behaviour goals

Prompt self-monitoring of behavioural determinant

Social support 
Table 1 Summary of the NULevel face-to-face weight loss maintenance consultation (Continued)

\begin{tabular}{lll}
\hline & previous week Explain options to contact the research team (by & \\
email, SMS and diary tick-box) & \\
& Identify situations in which participant struggles to be active & Barrier identification \\
& Participant generates "if ... then ..." formulations using a & Problem solving \\
& volitional helpsheet (Armitage 2014) physically drawing a line to & Coping planning \\
link situations with several possible solutions & \\
& Summarise eating, physical activity and weight goals Check \\
participant understanding of action plans, coping plans and & \\
self-monitoring procedures & \\
& Give participant written details of goals, online interface user \\
& guide, log-in details and (if desired) new WLM eating plan & \\
& Address remaining concerns, explain next steps and thank & \\
participant for their time & \\
\hline
\end{tabular}

SMART specific, measurable, attainable, relevant, time-based, SMS short message service, WLM weight loss maintenance

week. Finally, they learn how to edit, delete and create new dietary and physical activity goals for themselves.

\section{Daily weighing and weekly diary}

Participants in the NULevel intervention are instructed to weigh themselves daily, ideally at a consistent time and under similar circumstances (e.g. in the morning after emptying their bladder, before eating or drinking and dressed in underclothes only). To establish this weighing habit, participants are prompted by text message to weigh themselves if no weight report is received from their scales for 24 hours in the first 2 weeks of the intervention, and for 72 hours or more thereafter. Daily measurements from each individual are evaluated for implausible day-to-day fluctuations, triggering a check on whether the measurement came from a non-participant, e.g. a family member. NULevel intervention participants are able to see the weights sent by their SIM-enabled scales displayed on a graph using the online platform.

Once a week, participants receive a prompt to complete their diary entry and an SMS link through which they can do so. Once they have submitted information regarding their step counts, achievement towards behavioural goals, confidence and whether they need additional contact with an intervention facilitator, they receive immediate feedback via on-screen messages regarding their dietary and physical activity goal progress. When the goals are repeatedly achieved, participants are prompted to set new ones. If the goals are repeatedly missed, participants are prompted to develop new plans to achieve the goals, or to set alternative, more achievable goals. This is supported within their web-based intervention platform.

\section{Automated and tailored remote feedback}

Participants receive daily information and feedback from the study team. NULevel provides 'light touch' daily support in periods of successful WLM (i.e. while remaining in the green zone), which becomes more intensive during periods of weight gain (i.e. when moving into the yellow or red zones). Participants remaining in the green zone receive general tips and theory-based advice related to WLM as well as praise and reinforcement for keeping the weight off. If their weight enters the yellow or red zone, they receive tailored messages which support them to initiate a collaborative problem-solving process. This process is usually conducted via SMS between the research team member and the participant, but may include telephone calls if requested by the participant. Intervention content is based on six themes that were identified in a systematic review of behavioural theories [18] and in previous qualitative work [17] as relevant for behavioural change maintenance. These themes involve (a) sustainable motives for long-term WLM behaviours [27-30], (b) self-regulation and relapse prevention [25, 31-33], (c) management of personal resources [34], (d) habits and behavioural automaticity [30, 35, 36], (e) environmental and social influences [37] and (f) goal conflict, goal facilitation and priorities $[38,39]$.

If a participant's weight falls into the red zone, they are sent, via mail, a personalised parcel of materials to support and motivate them in managing their regain, including a cook book, stress ball, personalised materials and leaflets containing advice and encouragement. Further details of NULevel intervention and the green, yellow and red zones are provided in Table 2.

\section{Control arm}

For those allocated to the control arm, quarterly SMS messages are sent, containing links to evidence-based, weight management guidance. No further instructions regarding the use of the SIM-enabled scales are given. 
Table 2 Description of automated and manual SMS text messages in NULevel

\begin{tabular}{|c|c|c|c|c|c|}
\hline Construct & Sent to & Frequency & Trigger & $\begin{array}{l}\text { Automated/ } \\
\text { manual }\end{array}$ & Example \\
\hline \multicolumn{6}{|c|}{ Theoretical themes of maintenance } \\
\hline Motivation & $\begin{array}{l}\text { All } \\
\text { participants }\end{array}$ & Every 14 days & $\begin{array}{l}\text { Specified number } \\
\text { of days since } \\
\text { joining study }\end{array}$ & Automated & $\begin{array}{l}\text { Benefits of keeping weight off include better } \\
\text { health, self-confidence, new clothes, more energy } \\
\text { and a feeling of achievement. Think of what else } \\
\text { you'd add to this list. Tell us what motivates you } \\
\text { to maintain weight loss. }\end{array}$ \\
\hline Resources & & & & & $\begin{array}{l}\text { Sometimes we intend to be active but conclude ' } \\
\text { don't have time for this!' Do you do this? If so, } \\
\text { click: \{link: web content\}. }\end{array}$ \\
\hline Self-regulation & & & & & $\begin{array}{l}\text { Are you planning to eat out anytime soon? } \\
\text { Thinking ahead helps you stay in control: what } \\
\text { healthy option from the menu would you enjoy? }\end{array}$ \\
\hline Habits & & & & & $\begin{array}{l}\text { Creating new positive habits to keep weight off } \\
\text { takes time; you have to repeatedly do things to } \\
\text { build them into your routine (same place, same } \\
\text { time, same way). Try to stay positive: habits take } \\
\text { time to develop. }\end{array}$ \\
\hline $\begin{array}{l}\text { Environment } \\
\text { and social } \\
\text { influences }\end{array}$ & & & & & $\begin{array}{l}\text { Eating with supportive family or friends is } \\
\text { enjoyable and it can help keep your weight on } \\
\text { track too. If you need some inspiration, here are } \\
\text { some simple and delicious ideas: \{link: web } \\
\text { content\}. }\end{array}$ \\
\hline Behaviour & Sent to & Frequency & Trigger & $\begin{array}{l}\text { Automated/ } \\
\text { manual }\end{array}$ & Example \\
\hline
\end{tabular}

Prompt self-monitoring of behavioural goals

$\begin{array}{lll}\text { Physical } & \text { All } & \text { Every } 7 \text { days } \\ \text { activity and } & \text { participants } & \\ \text { eating } & & \end{array}$

Provide feedback on behaviour

$\begin{array}{lll}\text { Physical } & \text { All } & \text { Every } 7 \text { days } \\ \text { activity and } & \text { participants } & \\ \text { eating } & & \end{array}$

$$
\begin{array}{lll}
\text { Self-weighing } & \text { All } \\
\text { participants } & \text { Daily (days 1-7) } \\
& \text { Weekly (day } 8 \rightarrow \text { ) }
\end{array}
$$

\begin{tabular}{|c|c|c|c|}
\hline $\begin{array}{l}\text { Physical } \\
\text { activity and } \\
\text { eating }\end{array}$ & $\begin{array}{l}\text { All } \\
\text { participants }\end{array}$ & As required & $\begin{array}{l}\text { Participant meets } \\
\text { behavioural goals s } \\
\text { on } 3 \text { consecutive } \\
\text { wks }\end{array}$ \\
\hline Weight zone & Sent to & Frequency & Trigger \\
\hline \multicolumn{4}{|c|}{ Prompt self-monitoring of outcome (weight goal set in session) } \\
\hline All & As required & As required & $\begin{array}{l}\text { No weight in } 96 \\
\text { hrs }\end{array}$ \\
\hline All & All & Every 6 weeks & Specific dates \\
\hline
\end{tabular}

Prompt review of behavioural goals

Provide feedback on behavioural outcome
Participant enters activity and eating goal data

Participant selfweighs daily

Specified weekday* Automated Please complete your diary today, by following this link: \{link:diary\}.

Automated Thanks for submitting your activity and eating goal diary entries - they help you keep on track to meet your weight goal.

This week you missed your eating goals. Sticking to your plans is key to keeping the weight off! Follow this link \{link:plan\} to plan how, when and where you can meet your goals next week.

Thanks for weighing yourself - it's important for keeping the weight off!

You weighed yourself regularly this week: well done and keep it up.

Manual You have mastered your activity goals congratulations! Why not set yourself some new goals for next week, since you've mastered these ones? If so, follow this link to write a new plan \{link: edit plan\}. If not, you need do nothing.

Automated/ Example manual

Automated Don't forget to weigh yourself today - it's important for maintaining your weight loss.

Automated Have you looked at your weight graph recently? If not, simply log in at \{link: login\} and click 'weight' to view your progress. Log in details not working or forgotten? Please text back and we'll help! 
Table 2 Description of automated and manual SMS text messages in NULevel (Continued)

\begin{tabular}{|c|c|c|c|c|c|}
\hline Green & $\begin{array}{l}\text { All } \\
\text { participants }\end{array}$ & Every 7 days & $\begin{array}{l}\text { Weight stable in } \\
\text { green zone }\end{array}$ & Automated & $\begin{array}{l}\text { This week you managed to stick to your green } \\
\text { zone weight: good job. }\end{array}$ \\
\hline Yellow/red & As required & As required & $\begin{array}{l}\geq 4 \text { weights at or } \\
\text { above yellow/red } \\
\text { zone threshold }\end{array}$ & Manual & $\begin{array}{l}\text { We noticed that you regained some of your lost } \\
\text { weight and you are now in the yellow/red zone } \\
\text { you specified at our support session. Could you } \\
\text { please reply to this message to confirm that your } \\
\text { last few weights are correct? }\end{array}$ \\
\hline
\end{tabular}

Problem solving, action planning and coping planning; prompt focus on past success

$\begin{array}{lll}\text { Yellow/red As required } 2^{\text {nd }} \text { day in yellow/red zone } & \text { Participant } \\ & \text { confirms accuracy } \\ & \text { of recent weights }\end{array}$

Yellow/red As required As required

Yellow/red As required $2^{\text {nd }}$ day in yellow/red zone

Red

As required $3^{\text {rd }}$ day in red zone

Red

As required $4^{\text {th }}$ day in red zone; unscripted exchanges continue thereafter until weight loss achieved $\geq 4$ weights below Manual yellow/red zone threshold

Participant confirms accuracy of recent weights

Participant confirms wish to lose weight

Participant requests Automated ongoing support in weight loss

Automated

Automated

Okay, thanks for letting us know your recent weights are correct. We're here to help you get back on track. Would you like us to look at your diary entries and weight to produce some extra, positive, personalized feedback for you?

You're back in the green zone - congratulations for getting your weight back on track!

You're back in the yellow zone - congratulations!

What would you like to do about your regain? You may want to concentrate on just avoiding further regain, or instead to focus on losing the weight you've gained. We're here to support you, whatever you prefer. Please text us your preference.

Automated You've lost weight before, so you know a lot about which methods work for you and which don't. With that in mind, do you currently have a plan for how you'd like to lose weight? Alternatively, would you like our help in developing one? Please text back to let us know.

It's great to hear that you'd like our help in developing a plan to get your weight back on track. You're an expert on strategies that worked for you before - would you like your new plan to involve these?

We'd like to ask you more about your eating and activity over the last few weeks. This will help pinpoint the causes of your regain.

What would you say has affected your weight the most, recently?

Social support

Yellow/red As required As required
Participant requests Manual ongoing support in weight loss
Prompt review of outcome goal(s)

Green As required As required

Weight $\geq 1 \mathrm{~kg} \quad$ Manual below 'green zone'

Participant declines to lose weight following regain
We are glad to hear that you'd like our help in developing a plan to get your weight back on track. This is done most easily with a phone call: please text back CALL ME if you'd like a call, with a suitable day and time. Please text NO CALL if you don't want us to ring: we'll continue to support your plan development by SMS.

You're below your green zone weight, congratulations! Why not set yourself some lower thresholds for your yellow and red zone to help keep the weight off? Please text me back with the new weights if you'd like to change them - if not, you don't need to do anything. Thank you and well done.

Thanks for telling us you'd prefer to avoid further weight gain, but don't wish to lose weight at the moment. We are here to support and encourage you every step of the way. In this case, we reset your yellow zone weight to put you back into the green zone, then provide usual weight 
Table 2 Description of automated and manual SMS text messages in NULevel (Continued)

\begin{tabular}{|c|c|c|c|c|}
\hline & & & & $\begin{array}{l}\text { maintenance support. Are you happy for us to do } \\
\text { this? }\end{array}$ \\
\hline \multicolumn{5}{|l|}{ General } \\
\hline $\begin{array}{l}\text { Seasonal/ } \\
\text { date-based } \\
\text { (e.g. } 24 \\
\text { December) }\end{array}$ & $\begin{array}{ll}\text { All } & \text { On seasonal basis } \\
\text { participants } & \end{array}$ & Date & Automated & $\begin{array}{l}\text { Many people decide to throw dietary caution to } \\
\text { the wind on Christmas Day - don't worry, we } \\
\text { won't try to dissuade you! It's only one day of the } \\
\text { year. However, if you fancy a delicious, indulgent } \\
\text { Christmas Day that's (surprisingly) under } 2500 \\
\text { calories, then look no further: \{link: web content\}. }\end{array}$ \\
\hline
\end{tabular}

*If the input in question is not received within 24 hours (diary entry), a daily SMS reminder is sent until such input is received, or the participant opts out of receiving reminders. Minimum (possible) received SMS: 304; maximum (possible) received: 500 approx

SMS short message service

Participants can see their weight on the display of the scale, but no additional feedback on weight progress is provided. Participants are aware that the study team can access their weight data. There are no study-imposed constraints regarding the weight management behaviour of the control arm participants.

\section{Hypothesised mechanisms of impact}

The NULevel intervention is hypothesised to reduce weight regain compared to controls through the following mechanisms:

1. The initial face-to-face WLM consultation is hypothesised to correct any existing misperceptions about a healthy and sustainable diet, establish clear behavioural goals, action plans and coping plans as well as to enhance self-efficacy for successful weight management and relapse prevention [40-42].

2. The provision of wirelessly connected scales, pedometers and brief weekly goal progress questionnaires via mobile internet is hypothesised to increase the rate of self-weighing, self-monitoring of behaviour, and the use of self-regulation strategies [43-46]. Prompting participants to develop routines of monitoring progress on weight, physical activity and eating behaviour goals is hypothesised to be a key change mechanism in weight management $[15,26]$. Moreover, the regular self-monitoring allows individuals to focus their self-regulatory efforts on periods when WLM is more challenging, thereby conserving their psychological resources and avoiding intervention fatigue and ego depletion [34].

3. Theory-based text messages are hypothesised to support participants in focusing on motives which have been hypothesised to facilitate maintenance such as enjoyment of WLM behaviours [47], identity coherent with healthy lifestyle choices [46], selfdetermination [48], and satisfaction with weight outcomes [41]. Text messages also facilitate individual self-regulation $[15,43]$ and the development of healthy habits and routines [46]; they support the management of personal resources [34, 49], social and environmental challenges/opportunities [37], and goal conflicts and priorities [50].

4. Additional support in the yellow and red zone is hypothesised to help solving problems, managing temporary lapses and preventing relapses [32] as well as to provide social support [51].

5. Steps 1-4 are hypothesised to lead to healthier eating patterns [52], higher levels of physical activity and therefore reduced weight regain compared to controls. The maintenance of weight loss as well as the experience of control over one's body weight are hypothesised to result in higher quality of life [53].

\section{Outcomes}

The primary outcome is change in weight from baseline (i.e. randomisation) to 12 months. Secondary outcomes include weight-related anthropometric measures and self-reported measures related to the process and health economic evaluation of the study. A trained outcome assessor blinded to participant allocation status takes all anthropometric outcome measures and is present during the completion of questionnaire-based measures at the baseline and 12 months. An intermediate post-intervention assessment of questionnairebased outcomes at 6 months is conducted via postal questionnaires. Table 3 summarises the study measures.

\section{Anthropometric measures}

Body weight, clothed without shoes, is measured by an outcome assessor, not involved in any other aspect of the study and blinded to the participants' group allocation, to the nearest $0.1 \mathrm{~kg}$ using digital portable scales (SECA model 875) and height to the nearest $1 \mathrm{~mm}$ using a Leicester Height Measure stadiometer (both SECA UK Ltd: Birmingham, UK). BMI is calculated as body weight $(\mathrm{kg})$ divided by the square of height $(\mathrm{m})$. Waist circumference and hip circumference are recorded with an anthropometric tape measure, following established protocols [54]. Body fat percentage is 


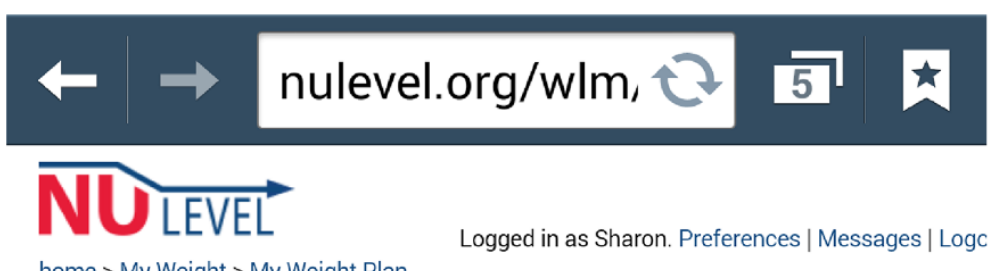

home $>$ My Weight $>$ My Weight Plan

\section{My Weight Plan}

$\begin{array}{ll}\text { Current Zone } & \text { Green } \\ \text { Weight Goal } & 91.6 \mathrm{~kg} \\ \text { Yellow Zone Threshold } & 93.4 \mathrm{~kg} \\ \text { Red Zone Threshold } & 95.2 \mathrm{~kg}\end{array}$

- Edit my plan

My Weight History

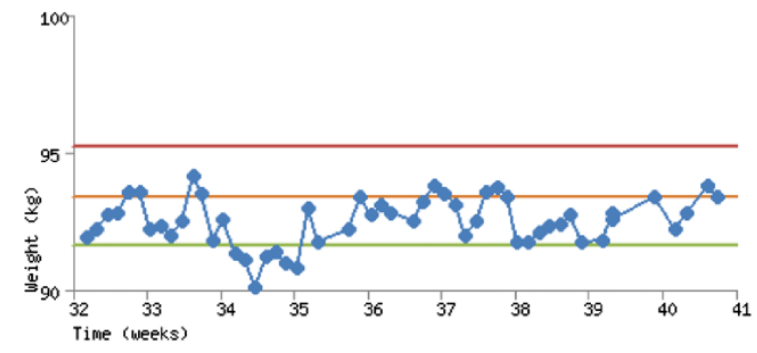

\begin{tabular}{|c|c|c|}
\hline Date $\uparrow$ & Weight & \\
\hline 01 Jun 2015 & $93.4 \mathrm{~kg}$ & Delete \\
\hline 31 May 2015 & $93.8 \mathrm{~kg}$ & Delete \\
\hline 29 May 2015 & $92.8 \mathrm{~kg}$ & Delete \\
\hline 28 May 2015 & $92.2 \mathrm{~kg}$ & Delete \\
\hline 26 May 2015 & $93.4 \mathrm{~kg}$ & Delete \\
\hline 22 May 2015 & $92.6 \mathrm{~kg}$ & Delete \\
\hline 22 May 2015 & $92.8 \mathrm{~kg}$ & Delete \\
\hline 21 May 2015 & $91.8 \mathrm{~kg}$ & Delete \\
\hline 19 May 2015 & $91.7 \mathrm{~kg}$ & Delete \\
\hline 18 May 2015 & $92.7 \mathrm{~kg}$ & Delete \\
\hline
\end{tabular}

Fig. 2 Screenshot of the NULevel mobile web interface

measured using an Omron BF306 handheld body fat monitor, whilst resting heart rate and blood pressure are measured using an Omron HEM-7200 arm cuff automatic BP monitor (both Omron Healthcare UK Ltd: Milton Keynes, UK). Physical activity is assessed using an ActiGraph@ GT3X+ (ActiGraph, LLC., Pensacola, FL, USA) accelerometer worn for at least 8 hours per day over 7 days. Height is measured once, at baseline; all other physical measurements are taken at baseline and 12-month follow-up.

\section{Questionnaire-based measures}

Participants complete a set of questionnaire-based measures at the baseline and 12-month follow-up visits in the presence of the trained outcome assessor. At 6 
Table 3 Schedule of assessments for NULevel trial

\begin{tabular}{|c|c|c|c|}
\hline Procedure & $\begin{array}{l}\text { Visit 1: baseline (screening/ } \\
\text { randomisation) }\end{array}$ & $\begin{array}{l}\text { Post-intervention assessment ( } 6 \\
\text { months) }\end{array}$ & $\begin{array}{l}\text { Visit } 2 \text { (12 } \\
\text { months) }\end{array}$ \\
\hline Informed consent & $x$ & & \\
\hline Demographic details (and address) & $x$ & & \\
\hline Blood pressure & $x$ & & $x$ \\
\hline Resting heart rate & $x$ & & $x$ \\
\hline Body weight & $x$ & & $x$ \\
\hline Height & $x$ & & \\
\hline $\begin{array}{l}\text { Body composition (hip/waist circumference; \% } \\
\text { body fat) }\end{array}$ & $x$ & & $x$ \\
\hline Physical activity (ActiGraph@ GT3X+) & $x$ & & $x$ \\
\hline Economic assessments & $x$ & $x$ & $x$ \\
\hline Psychological assessments & $\mathrm{x}$ & $x$ & $x$ \\
\hline
\end{tabular}

Questionnaires were self-completed by participants. Assessors were trained to answer general questions

months, participants receive, self-complete, and return the questionnaire battery via post or online depending on their preference. This questionnaire includes measures of:

1. Health-related quality of life, assessed using the EQ5D 3L [53] and healthcare costs and service usage, assessed using a structured questionnaire that was designed bespoke for this study from an existing item bank and a database of tools (www.dirum.ac.uk)

2. Satisfaction with weight outcomes, assessed by the Weight Outcomes Satisfaction Scale [41]

3. Self-efficacy for WLM, physical activity and healthy eating $[42,55]$

4. Action planning and coping planning [40]

5. Eating attitudes and behaviours, assessed using the revised 18-item version of the Three-Factor Eating Questionnaire (TFEQ-R18) [52, 56]

6. Automaticity and identity, assessed by the SelfReport Behavioural Automaticity Index, also called the automaticity-specific Self-Report Habit Index subscale $[46,57]$

7. Use of self-regulation strategies [43-45]

8. Ego depletion (a measure developed for this study)

9. Self-determination for weight control [48]

10.Social support, assessed using the ENRICHD Social Support Inventory [51]

11.Frequency and place of weighing (generic item)

Table 3 summarises the frequency and timing of assessments.

\section{Process evaluation}

A mixed methods process evaluation is being conducted to evaluate the implementation of the intervention and the mechanisms of potential impact. Furthermore, an examination of the effect of contextual factors on interventoin implementation and mechanisms is underway [58].

Quantitative indices by which process evaluation is undertaken include:

1. Timing and frequency of self-weighing in both trial arms (as automatically recorded by the SIM-enabled scales),

2. Usage data for intervention components, including completed phone calls, patient-initiated personal contact, frequency and duration of software module access, frequency of online eating and physical activity self-monitoring, number and nature of semiautomated intervention contacts) and

3. Secondary outcome variables (as assessed via the questionnaire-based measures) assessing theoretical intervention targets.

A qualitative process evaluation is also being conducted through theory-based semi-structured interviews $[59,60]$ with 40 randomly selected participants in their first 6 months in the trial following randomisation.

\section{Fidelity assurance}

Fidelity checks will be conducted to ensure consistency and adequacy of the face-to-face intervention sessions in delivering the specified session content and behaviour change strategies. A randomly chosen set of audio recordings of 20 initial advice/goal setting sessions and randomly chosen set of intervener-participant telephone contacts (summarised in written form using study-specific contact sheets) are being assessed. Interviews are transcribed verbatim. Data from the interviews and telephone contact sheets are entered into Nvivo and comparatively analysed against the intervention techniques [61] specified for the respective intervention component. 


\section{Sample size calculation}

The power analysis was informed by recent systematic reviews of RCTs of weight loss maintenance interventions $[8,9]$. In order to detect a $2.5 \mathrm{~kg}$ between-groups mean difference in weight gain at 12 months, given a type 1 error rate of $5 \%$ and assuming a standard deviation of weight gain of $6 \mathrm{~kg}$ with $90 \%$ statistical power, two groups of 122 participants providing data on the primary outcome are required. Assuming a rate of $15 \%$ loss to followup, a total sample of 288 randomised participants is needed. The parameters of this power calculation are derived from comparative behavioural WLM trials $[13-15,51]$. The aim of the intervention is to flatten the typically observed weight regain curve.

\section{Randomisation and allocation concealment}

Randomisation occurs in a 1:1 ratio (144 in each arm), and is stratified by sex and prior weight loss $<10 \%$ vs $\geq 10 \%$. A secure web-based randomisation system based on variablelength blocks, provided by Newcastle Clinical Trials Unit via Data Architects Ltd. (Newcastle upon Tyne, UK), is used to ensure concealment of allocation. The nature of the intervention is such that participants cannot be blinded, post-randomisation, as to their allocation status. Outcome assessors are blinded. When invited to attend follow-up assessments, participants are asked not to disclose their trial allocation to the outcome assessor. A record is kept to document all instances where participants reveal information about their trial allocation to the assessor.

\section{Data handling and record keeping}

Data are being collected centrally and recorded automatically by a secure system devised specifically for this study. Data are being handled, digitised and stored in accordance with the Data Protection Act 1998. No participant identifiable data will leave the study site. Participants are identified within data collection systems by a unique identification number. The quality and retention of study data and data management is the responsibility of the Chief Investigator. All study data will be retained in accordance with the latest Directive on Good Clinical Practice (2005/28/EC) and local policy.

\section{Statistical methods}

Specific analyses relate to each of the study objectives.

\section{Effectiveness analyses}

The main aim of the intervention is to help participants avoid regaining weight. The primary outcome is change in weight at 12 months post-randomisation relative to baseline. This will be analysed using analysis of covariance assuming a normal error structure. The dependent variable will be weight at 12 months post-randomisation. Baseline weight will be included as a covariate. Fixed effects will include two factors defining the stratification of the sample (sex of the participant and a binary indicator of whether the participant lost more than $10 \%$ of their body weight) and a difference between the randomised trial arms (corresponding to an intention-to-treat analysis). Results will be in the form of a $95 \%$ confidence interval for the mean difference in weight between participants randomised to the novel intervention and participants randomised to the control arm. If the standardised residuals are not normally distributed, an alternative confidence interval will be calculated using resampling (bootstrap) procedures. The impact of missing data will be assessed using a sensitivity analysis. Any data imputation will depend upon the level of missing data and its pattern. There will be no interim analysis. Secondary outcomes will be analysed using the same approach with an appropriate error structure adopted for each particular measure. Where appropriate, mediation analyses will be conducted to test if any observed effects of the NuLevel intervention are statistically accounted for by effects of psychological process measures.

\section{Analysis of relationships between socioeconomic and demographic factors with WLM}

The association between WLM and socioeconomic and demographic factors will be evaluated. The English Indices of Multiple Deprivation (IMD will be identified for each participant, matched to their seven-digit unit postcode. Other demographic variables will be collected in questionnaires at baseline. Relationships between age, sex, income band, education, IMD rank, employment status, car and home ownership, baseline BMI and pretrial weight loss experience will be examined. We will extend the models used to estimate effectiveness with the inclusion of appropriate explanatory variables and interaction terms.

Data from exploratory analyses will be used to complement and inform the economic evaluation, thereby providing information to guide judgements as to how to reduce inequalities stemming from differences in effectiveness of WLM interventions and address necessary trade-offs between overall effectiveness and equity.

\section{Health economics analyses}

In order to estimate the cost-effectiveness of WLM in the RCT, a within-trial economic analysis will estimate the incremental cost per unit difference in weight regain. Costs will be based upon intervention costs (actual) and costs of any additional services used or incurred by participants. With respect to the intervention costs we aim to develop this intervention so that it could be delivered to the $>93 \%$ of the population that currently owns a mobile phone, for under $£ 100$ ( + costs of personal contact). Analyses will draw on data from the 
Healthcare Usage Questionnaire and quality-adjusted life years (QALYs) will be estimated using the EQ-5D 3L. Extrapolation beyond the trial will be based upon a state transition model drawing on previous work of the coapplicants. The results will be presented as an incremental cost per QALY gained. Costs, health state utilities and the probabilities of future events required to populate the model will be based upon our prior work and structured reviews of the literature. Both probabilistic (to explore the impact of statistical imprecision) and deterministic models (to explore other uncertainties and scenarios - e.g. the impact of a less intensive intervention) will be explored. The perspective of the analysis is the National Health Service (NHS), other care providers and the participant.

\section{Compliance and withdrawal}

Compliance with outcome assessment is evaluated by the outcome assessor and by the completion rates of the study questionnaires. Compliance with the intervention is assessed via the frequency of self-weighing, attendance at the intervention session and by usage statistics for the intervention platform, as accessed by participants as part of the digital component of the intervention. Standard operating procedures for dealing with non-responders and with participant withdrawal are followed (Appendix A).

\section{Internal pilot study}

An internal pilot study to evaluate the acceptability and feasibility of the trial procedures (e.g. recruitment, measurement, allocation and retention procedures) was completed in July 2014 before proceeding with the full trial. Progression to a full trial required that, in the first 3 months of the trial, the team (1) recruited, consented and randomised $\geq 50$ participants, (2) established evidence, through participant feedback, of the acceptability of trial procedures, and (3) sustained less than $20 \%$ participant loss to follow-up in data collection. All three targets were met, which allowed continuation to the full trial without changes to the protocol. Therefore, the data obtained during the internal pilot period will form part of the trial dataset.

\section{Discussion}

This is the first randomised trial to test the effectiveness of a WLM intervention utilising ubiquitous technology to tailor an evidence-informed intervention to obese adults who have lost a clinically significant amount of their body weight. The study includes an economic cost-effectiveness evaluation. This trial will provide policy makers and commissioners with the evidence to decide whether to adopt this method to support obese adults who have lost weight. Cost-effective
WLM interventions are a vital complement to existing services targeting weight loss, including commercial weight management programmes. They also potentially benefit healthcare services that directly and indirectly target obesity, and cope with its consequences.

The current study addresses research needs identified by a recent systematic review $[9,62]$ :

1. All but three $[15,22,23]$ RCTs identified in this review included an initial period of facilitated weight loss, mostly through very low-energy diets. While this procedure is practical for research, it might limit generalisability and does not easily translate to a public health prevention approach.

2. Most effective WLM interventions to date have been highly resource intensive and hence not scalable, i.e. practical for widespread implementation.

3. Previous attempts to use technology to make interventions flexible, efficient and scalable have not used contemporary digital technologies.

Interventions using the internet for intervention delivery were not effective [15, 63-65].

In the NULevel trial, the first research gap is addressed by including participants drawn from a wide range of settings, to more closely reflect weight management practices of the population. This includes participants engaged with commercial and community-based weight loss programmes as well as those who lost weight independently of professional support. The second and third main research gaps are interrelated because effective technology use could help to make interventions both more accessible and affordable. Rather than delivering interventions if and when participants use their computer to browse the internet, mobile phone platforms provide more promising modes of delivery because they allow immediate access to information in any situation and context. Feature phones (i.e. standard mobile phones with access to the internet) and smart phones are ubiquitous in both developed and developing economies, and provide a robust technology platform for cost-effective delivery and rollout of interventions. In the UK, $93 \%$ of the adult population owns a mobile phone that can be used to access the internet and coverage is good even among the most deprived households $(87 \%)$ and in the $75+$ age group $(58 \%)$. These figures are rising and compare very favourably with access rates to home computers with internet connectivity ( $71 \%$ of UK households; $54 \%$ in the most deprived households; $25 \%$ for $65+$ age group) [66]. There is good evidence for the acceptability and effectiveness of mobile phonedelivered interventions from weight loss studies [67-69].

The NULevel trial will inform how best to encourage and enable WLM in obese adults who have successfully 
lost weight. It will show if a theory- and evidence-informed intervention based on interactive digital technology is costeffective in supporting WLM. Further, it will indicate whether the resulting NULevel intervention platform is an efficient means of utilising limited resources (such as staff time) to optimise outcomes in populations, and what level of additional personal support is needed to obtain optimal outcomes per investment.

Obesity remains a growing and intolerable burden on services and society, and thus finding cost-effective means to help sustain effects of weight loss interventions is vital for international public health.

\section{Trial status}

The trial described in this protocol is now at the recruitment, post-pilot stage.

\section{Endnotes}

${ }^{1}$ The technology for the scales has been released as WeighAX, part of the Open Movement open-source project (http://openmovement.co.uk).

\section{Abbreviations \\ BMI: body mass index; IMD: Index of Multiple Deprivation; NHS: National Health Service; QALY: quality-adjusted life year; RCT: randomised controlled trial; SMS: short message service; UK: United Kingdom; US: United States; WLM: weight loss maintenance.}

\section{Competing interests}

The authors and investigators have no competing interests to disclose.

\begin{abstract}
Authors' contributions
EHE contributed to the development and delivery of the intervention and to the design and coordination of the study and she drafted the manuscript. $A A, V A S, A M B, P O, M W$ and PW contributed to the conception and design of the study and the development of the intervention. MC contributed to the design and the delivery of the study. $\mathrm{HB}, \mathrm{EM}$ and LV contributed to the conception and design of the study. SUD and AJR contributed to the design of the study and the development of the intervention. AG performed the blind outcome assessment. DJ designed and developed the NULevel digital platform software. KL designed and developed the NULevel digital platform hardware for the scales. DK contributed to the development of the intervention and the delivery of the study. KS contributed to the coordination of the study and the delivery of the intervention and she helped drafting the manuscript. AJS is the trial manager. INS contributed to the design of the study and developed the statistical data analysis strategy. FFS is the principal investigator, conceived of the study, contributed to the design and coordination of the study, the development of the intervention and helped drafting the manuscript. All authors read and approved the final manuscript.
\end{abstract}

\section{Acknowledgements}

The study is funded by the UK National Prevention Research Initiative (NPRI) Phase 4 (grant MR/J000477/1). The NPRI includes the following Funding Partners (in alphabetical order): Alzheimer's Research Trust, Alzheimer's Society, Biotechnology and Biological Sciences Research Council, British Heart Foundation, Cancer Research UK, Chief Scientist Office, Scottish Government Health Directorate, Department of Health, Diabetes UK, Economic and Social Research Council, Health and Social Care Research and Development Division of the Public Health Agency (HSC \& R\&D Division), Medical Research Council, The Stroke Association, Wellcome Trust, Welsh Assembly Government and World Cancer Research Fund. FFS is funded by Fuse, the Centre for Translational Research in Public Health, a UKCRC Public Health Research Centre of Excellence based on funding from the British
Heart Foundation, Cancer Research UK, Economic and Social Research Council, Medical Research Council, and the National Institute for Health Research, under the auspices of the UK Clinical Research Collaboration. AA is funded by the National Institute of Health Research as an NIHR Research Professor.

The sponsor for this study is Public Health England. A Trial Oversight Committee (TOC) was appointed and is responsible for overseeing the progress of the trial. The TOC comprises Professor Shaun Treweek (chair), Dr Sharon Simpson (academic member), Dr Kim Cocks (statistician), Mrs Julia Catherine Smith (lay member) and Mrs Beverly May (lay member). The authors would like to thank Dr Elizabeth Coates from Public Health England and the members of the TOC for the ongoing support of the NULevel trial.

\section{Author details}

${ }^{1}$ Institute of Health \& Society, Newcastle University, Baddiley-Clark Building, Richardson Road, Newcastle upon Tyne NE2 4AX, UK. ${ }^{2}$ Fuse, the UK CRC Centre for Translational Research in Public Health, Institute of Health \& Society, Newcastle University, Baddiley-Clark Building, Richardson Road, Newcastle upon Tyne NE2 4AX, UK. ${ }^{3}$ Human Nutrition Research Centre, Institute of Health \& Society, University of Newcastle, William Leech Building, Medical School, Framlington Place, Newcastle upon Tyne NE2 4HH, UK. ${ }^{4}$ Health and Social Care Institute, Teesside University, Parkside WestMiddlesbrough, Tees Valley TS1 3BA, UK. ${ }^{5}$ School of Natural Sciences, Division of Psychology, University of Stirling, Stirling FK9 4LA, UK. ${ }^{6}$ Open Lab, School of Computing Science, Newcastle University, 89 Sandyford Road, Newcastle upon Tyne NE1 8HW, UK. ${ }^{7}$ Department of Psychology, University of Minnesota, 75 East River Road, Minneapolis, MN 55455, USA. ${ }^{8}$ Centre for Diet and Activity Research (CEDAR), MRC Epidemiology Unit, School of Clinical Medicine, University of Cambridge, Institute of Metabolic Science, Cambridge Biomedical Campus, Cambridge CB2 0QQ, UK. ${ }^{9}$ Newcastle Clinical Trials Unit, Newcastle University, 1-4 Claremont Terrace, Newcastle upon Tyne NE2 4AE, UK.

Received: 2 June 2015 Accepted: 27 August 2015

Published online: 22 September 2015

\section{References}

1. Wang YC, McPherson K, Marsh T, Gortmaker SL, Brown M. Health and economic burden of the projected obesity trends in the USA and the UK. Lancet. 2011;378:815-25.

2. Government Office for Science. Tackling obesities: future choices. 2007. https:// www.gov.uk/government/publications/reducing-obesity-future-choices. Accessed 3 March 2015

3. Excellence NIfHaC. Managing overweight and obesity in adults - lifestyle weight management services. 2014. https://www.nice.org.uk/guidance/ph53. Accessed 17 June 2014

4. Avenell A, Broom J, Brown TJ, Poobalan A, Aucott L, Stearns SC, et al. Systematic review of the long-term effects and economic consequences of treatments for obesity and implications for health improvement. Health Technol Assess. 2004;8(iii-iv):1-182.

5. Dombrowski SU, Avenell A, Sniehotta FF. Behavioural interventions for obese adults with additional risk factors for morbidity: systematic review of effects on behaviour, weight and disease risk factors. Obes Facts. 2010;3:377-96

6. Jolly K, Lewis A, Beach J, Denley J, Adab P, Deeks JJ, et al. Comparison of range of commercial or primary care led weight reduction programmes with minimal intervention control for weight loss in obesity: Lighten Up randomised controlled trial. BMJ. 2011;343:d6500.

7. Penn L, White M, Lindström J, den Boer AT, Blaak E, Eriksson JG, et al. Importance of weight loss maintenance and risk prediction in the prevention of type 2 diabetes: analysis of European Diabetes Prevention Study RCT. PLoS One. 2013;8, e57143.

8. Middleton KM, Patidar SM, Perri MG. The impact of extended care on the long-term maintenance of weight loss: a systematic review and metaanalysis. Obes Rev. 2012;13:509-17.

9. Dombrowski SU, Knittle K, Avenell A, Araújo-Soares V, Sniehotta FF. Long term maintenance of weight loss with non-surgical interventions in obese adults: systematic review and meta-analyses of randomised controlled trials. BMJ. 2014;348:g2646.

10. Sniehotta FF, Simpson S, Greaves CJ. Weight loss maintenance: an agenda for health psychology. Br J Health Psychol. 2014;19:459-64. 
11. Craig P, Dieppe P, Macintyre S, Michie S, Nazareth I, Petticrew M. Developing and evaluating complex interventions: the new Medical Research Council guidance. BMJ. 2008;337:a1655.

12. Wing RR, Phelan S. Long-term weight loss maintenance. Am J Clin Nutr. 2005;82 Suppl 1:222S-5S.

13. Madigan CD, Aveyard P, Jolly K, Denley J, Lewis A, Daley AJ. Regular selfweighing to promote weight maintenance after intentional weight loss: a quasi-randomized controlled trial. J Public Health. 2014;36:259-67.

14. Pacanowski CR, Bertz F, Levitsky DA. Daily self-weighing to control body weight in adults a critical review of the literature. SAGE Open. 2014;4:2158244014556992.

15. Wing RR, Tate DF, Gorin AA, Raynor HA, Fava JL. A self-regulation program for maintenance of weight loss. N Engl J Med. 2006;355:1563-71.

16. Ofcom. The communications market report 2014. http://stakeholders.ofcom .org.uk/binaries/research/cmr/cmr14/2014_UK_CMR.pdf. Accessed 20 October 2014

17. Kwasnicka D, Dombrowski SU, White M, Sniehotta FF. A qualitative dataprompted study of weight loss maintenance experiences using individual ecological data. Eur Health Psychol. 2015 (in press)

18. Kwasnicka D, White M, Dombrowski SU, Sniehotta FF. How can people maintain a new health behaviour? A theory review. Oxford: 9th Annual Scientific Meeting of the UK Society of Behavioural Medicine; Oxford, 2013.

19. Thomas JG, Bond DS, Phelan S, Hill JO, Wing RR. Weight-loss maintenance for 10 years in the National Weight Control Registry. Am J Prev Med. 2014;46:17-23.

20. Poltawski L, Greaves CJ, Garside R, Briscoe S. Weight loss maintenance - the perspectives and experiences of overweight people: a synthesis of qualitative evidence. PROSPERO 2014:CRD42014008666. http:// www.crd.york.ac.uk/PROSPERO/display_record.asp?ID=CRD42014008666. Accessed 30 January 2015

21. Penn L, Dombrowski SU, Sniehotta FF, White M. Participants' perspectives on making and maintaining behavioural changes in a lifestyle intervention for type 2 diabetes prevention: a qualitative study using the theory domain framework. BMJ Open. 2013;3, e002949.

22. Sherwood NE, Crain AL, Martinson BC, Anderson CP, Hayes MG, Anderson $J D$, et al. Enhancing long-term weight loss maintenance: 2 year results from the Keep It Off randomized controlled trial. Prev Med. 2013;56:171-7.

23. Dale KS, McAuley KA, Taylor RW, Williams SM, Farmer VL, Hansen P, et al. Determining optimal approaches for weight maintenance: A randomized controlled trial. Can Med Assoc J. 2009;180:E39-46.

24. Tan KCB. Appropriate body mass index for Asian populations and its implications for policy and intervention strategies. Lancet. 2004;363:157-63.

25. Kanfer FH, Goldstein AP. Helping people change. Elmsford: Pergamon Press; 1975

26. Dombrowski SU, Sniehotta FF, Avenell A, Johnston M, MacLennan G, Araújo-Soares $\mathrm{V}$. Identifying active ingredients in complex behavioural interventions for obese adults with obesity-related co-morbidities or additional risk factors for co-morbidities: a systematic review. Health Psychol Rev. 2012;6:7-32

27. Higgins ET. Value from hedonic experience and engagement. Psychol Rev. 2006;113:439-60.

28. Deci EL, Ryan RM. The "what" and "why" of goal pursuits: human needs and the self-determination of behavior. Psychol Inq. 2000;11:227-68.

29. Rothman AJ. Toward a theory-based analysis of behavioral maintenance. Health Psychol. 2000;19 Suppl 1:64-9.

30. Rothman AJ, Sheeran P, Wood W. Reflective and automatic processes in the initiation and maintenance of dietary change. Ann Behav Med. 2009;38 Suppl 1:S4-17.

31. Carver CS, Scheier MF. Control theory: a useful conceptual framework for personality-social, clinical, and health psychology. Psychol Bull. 1982;92:111-35.

32. Marlatt GA, Donovan DM, editors. Relapse prevention - maintenance strategies in the treatment of addictive behaviours, 2nd edn. New York: Guilford Press; 2005

33. Perri MG, Nezu AM. V BJ. Improving the long-term management of obesity. New York: Wiley; 1992

34. Baumeister RF. Ego depletion and self-control failure: an energy model of the self's executive function. Self Identity. 2002;1:129-36.

35. Wood W, Neal DT. A new look at habits and the habit-goal interface. Psychol Rev. 2007;114:843-63.

36. Gardner B. DOI: A review and analysis of the use of 'habit' in understanding, predicting and influencing health-related behaviour. Health Psychol Rev. 2014;Jan 21:1-19.
37. Bandura A. Social foundations of thought and action: a social cognitive theory. New York: Englewood Cliffs; 1986.

38. Presseau J, Sniehotta FF, Francis JJ, Gebhardt WA. With a little help from my goals: integrating intergoal facilitation with the theory of planned behaviour to predict physical activity. Br J Health Psychol. 2010;15:905-19.

39. Stroebe W, Mensink W, Aarts H, Schut H, Kruglanski AW. Why dieters fail: testing the goal conflict model of eating. J Exp Soc Psychol. 2008;44:11.

40. Sniehotta FF, Schwarzer R, Scholz U, Schüz B. Action planning and coping planning for long-term lifestyle change: theory and assessment. Eur I Soc Psychol. 2005;35:565-76.

41. Finch EA, Linde JA, Jeffery RW, Rothman AJ, King CM, Levy RL. The effects of outcome expectations and satisfaction on weight loss and maintenance: correlational and experimental analyses - a randomized trial. Health Psychol. 2005:24:608-16.

42. Schwarzer R, Renner B. Health-specific self-efficacy scales. 2009. http://userpage.fuberlin.de/health/healself.pdf. Accessed 9 November 2013

43. Sniehotta FF, Scholz U, Schwarzer R. Bridging the intention-behaviour gap: Planning, self-efficacy, and action control in the adoption and maintenance of physical exercise. Psychol Health. 2005;20:143-60.

44. Fuglestad PT, Rothman AJ, Jeffery RW. Getting there and hanging on: the effect of regulatory focus on performance in smoking and weight loss interventions. Health Psychol. 2008;27 Suppl 3:\$260-70.

45. Shah J, Higgins T, Friedman RS. Performance incentives and means: how regulatory focus influences goal attainment. J Pers Soc Psychol. 1998;74:285-93.

46. Verplanken B, Orbell S. Reflections on past behavior: a self-report index of habit strength. J Appl Soc Psychol. 2003;33:1313-30.

47. Hall PA, Fong GT. Temporal self-regulation theory: a model for individual health behavior. Health Psychol Rev. 2007:1:6-52.

48. Ryan RM, Connell JP. Perceived locus of causality and internalization: examining reasons for acting in two domains. J Pers Soc Psychol. 1989;57:749-61.

49. Hagger MS, Wood C, Stiff C, Chatzisarantis NL. Ego depletion and the strength model of self-control: a meta-analysis. Psychol Bull. 2010;136:495-525.

50. Presseau J, Tait RI, Johnston DW, Francis JJ, Sniehotta FF. Goal conflict and goal facilitation as predictors of daily accelerometer-assessed physical activity. Health Psychol. 2013;32:1179-87.

51. Mitchell PH, Powell L, Blumenthal J, Norten J, Ironson G, Pitula CR, et al. A short social support measure for patients recovering from myocardial infarction: the ENRICHD Social Support Inventory. J Cardpulm Rehabil. 2003;23:398-403

52. Karlsson J, Persson LO, Sjöström L, Sullivan M. Psychometric properties and factor structure of the Three-Factor Eating Questionnaire (TFEQ) in obese men and women. Results from the Swedish Obese Subjects (SOS) study. Int J Obes Relat Metab Disord. 2000;24:1715-25.

53. Dolan P. Modelling valuations for health states: the effect of duration. Health Policy. 1996;38:189-203.

54. World Health Organization. Waist circumference and waist-hip ratio: report of a WHO expert consultation. Geneva: WHO; 2011

55. Clark MM, Abrams DB, Niaura RS, Eaton CA, Rossi JS. Self-efficacy in weight management. J Consult Clin Psychol. 1991;59:739-44.

56. Stunkard AJ, Messick S. The three-factor eating questionnaire to measure dietary restraint, disinhibition and hunger. J Psychosom Res. 1985;29:71-83.

57. Gardner B, Abraham C, Lally P, de Bruijn G-J. Towards parsimony in habit measurement: Testing the convergent and predictive validity of an automaticity subscale of the Self-Report Habit Index. Int J Behav Nutr Phys Act. 2012:9:102.

58. Moore GF, Audrey S, Marker M, Bond L, Bonell C, Hardeman W, et al. Process evaluation of complex interventions: Medical Research Council guidance. BMJ. 2015;350:h1258.

59. Michie S, Johnston M, Abraham C, Lawton R, Parker D, Walker A. Making psychological theory useful for implementing evidence based practice: a consensus approach. Qual Saf Health Care. 2005;14:26-33.

60. Oakley A, Strange V, Bonell C, Allen E, Stephenson J. Process evaluation in randomised controlled trials of complex interventions. BMJ. 2006;332:413-6

61. Michie S, Ashford S, Sniehotta FF, Dombrowski SU, Bishop A, French DP. A refined taxonomy of behaviour change techniques to help people change their physical activity and healthy eating behaviours: The CALO-RE taxonomy. Psychol Health. 2011;26:1479-98.

62. Dombrowski SU, Knittle K, Avenell A, Araújo-Soares V, Sniehotta FF. Long term maintenance of weight loss with non-surgical interventions in obese 
adults: systematic review and meta-analyses of randomised controlled trials. BMJ. 2014;1-12.

63. Cussler EC, Teixeira PJ, Going SB, Houtkooper LB, Metcalfe LL, Blew RM, et al. Maintenance of weight loss in overweight middle-aged women through the internet. Obesity. 2008;16:1052-60.

64. Harvey-Berino J, Pintauro S, Buzzell P, DiGuilio M, Gold BC, Moldovan C, et al. Does using the Internet facilitate the maintenance of weight loss? Int J Obes. 2002;26:1254-60.

65. Harvey-Berino J, Pintauro S, Buzzell P, Gold EC. Effect of internet support on the long-term maintenance of weight loss. Obes Res. 2004;12:320-9.

66. Ofcom. The communications market report. 2010. http://stakeholders.ofcom org.uk/market-data-research/market-data/communications-market-reports/cmr10. Accessed 10 December 2013

67. Haapala I, Barengo NC, Biggs S, Surakka L, Manninen P. Weight loss by mobile phone: a 1-year effectiveness study. Public Health Nutr. 2009;12:2382-91

68. Gerber BS, Stolley MR, Thompson AL, Sharp LK, Fitzgibbon ML. Mobile phone text messaging to promote healthy behaviors and weight loss maintenance: a feasibility study. Health Informatics J. 2009;15:17-25.

69. Patrick K, Raab F, Adams MA, Dillon L, Zabinski M, Rock CL, et al. A text message-based intervention for weight loss: randomized controlled trial. J Med Internet Res. 2009;11, e1.

\section{Submit your next manuscript to BioMed Central and take full advantage of:}

- Convenient online submission

- Thorough peer review

- No space constraints or color figure charges

- Immediate publication on acceptance

- Inclusion in PubMed, CAS, Scopus and Google Scholar

- Research which is freely available for redistribution 